Article

\title{
Convective Initiation Proxies for Nowcasting Precipitation Severity Using the MSG-SEVIRI Rapid Scan
}

\author{
Donatello Gallucci ${ }^{1, *(\mathbb{C})}$, Maria Pia De Natale ${ }^{1}$, Domenico Cimini $\left.{ }^{1,2}{ }^{(}\right)$, Francesco Di Paola ${ }^{1}(\mathbb{D}$,

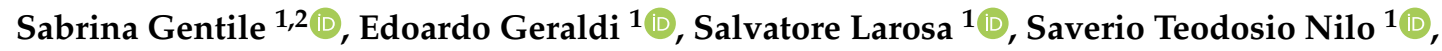 \\ Elisabetta Ricciardelli ${ }^{1}$, Mariassunta Viggiano ${ }^{1(D)}$ and Filomena Romano ${ }^{1}$ (D) \\ 1 Institute of Methodologies for Environmental Analysis, National Research Council (IMAA/CNR), \\ 85100 Potenza, Italy; mariapia.denatale@imaa.cnr.it (M.P.D.N.); domenico.cimini@imaa.cnr.it (D.C.); \\ francesco.dipaola@imaa.cnr.it (F.D.P.); sabrina.gentile@imaa.cnr.it (S.G.); edoardo.geraldi@imaa.cnr.it (E.G.); \\ salvatore.larosa@imaa.cnr.it (S.L.); saverio.nilo@imaa.cnr.it (S.T.N.); elisabetta.ricciardelli@imaa.cnr.it (E.R.); \\ mariassunta.viggiano@imaa.cnr.it (M.V.); filomena.romano@imaa.cnr.it (F.R.) \\ 2 Center of Excellence Telesensing of Environment and Model Prediction of Severe events (CETEMPS), \\ University of L'Aquila, 67100 L'Aquila, Italy \\ * Correspondence: donatello.gallucci@imaa.cnr.it; Tel.: +39-0971-427290
}

Received: 29 June 2020; Accepted: 6 August 2020; Published: 9 August 2020

\begin{abstract}
In this study, we investigate the ability of several convective initiation predictors based on satellite infrared observations to distinguish convective weak precipitation events from those leading to intense rainfall. The two types of precipitation are identified according to hourly rainfall, respectively less than $10 \mathrm{~mm}$ and greater than $30 \mathrm{~mm}$. The analysis is conducted on a representative dataset containing 92 severe and weak precipitation events collected over the Italian peninsula in the period 2016-2019 over June-September. The events are selected to be short-lived (i.e., less than $12 \mathrm{~h}$ ) and localized (i.e., less than $50 \times 50 \mathrm{~km}^{2}$ ). Italian National Radar Network products, namely the Vertical Maximum Intensity (VMI) and the Surface Rain Total (SRT) variables (from Dewetra Platform by CIMA, Italian Civil Protection Department), are used as indicators of convection (i.e., VMI greater than $35 \mathrm{dBZ}$ echo intensity) and cumulated rainfall, respectively. The considered predictors are linear combinations of spectral infrared channels measured with the Rapid Scan Service (RSS) Spinning Enhanced Visible and InfraRed Imager (SEVIRI) aboard Meteosat Second Generation (MSG) geostationary satellites. We select a $5 \times 5$ SEVIRI pixel-box centered on the storm core and perform a statistical analysis of the predictors up to $2.5 \mathrm{~h}$ around the event occurrence. We demonstrate that some of the proxies-describing growth and glaciation storm properties-show few degrees contrast between severe and nonsevere precipitation cases, hence carrying significant information to help discriminate the two types. We design a threshold scheme based on the three most informative predictors to distinguish weak and strong precipitation events. This analysis yields accuracy higher than 0.6 and the probability of false detection lower than 0.26 ; in terms of reducing false alarms, this method shows slight better performances compared to related works, at the expense of a lower probability of detection. The overall results, however, show limited capability for these infrared proxies as stand-alone predictors to distinguish severe from nonsevere precipitation events. Nonetheless, these may serve as additional tools to reduce the false alarm ratio in nowcasting algorithms for convective orographic storms. This study also provides further insight into the correlation between early infrared fields signatures prior to convection and subsequent evolution of the storms, extending previous works in this field.
\end{abstract}

Keywords: SEVIRI rapid scan; convection; infrared proxy; storm severity; nowcasting 


\section{Introduction}

The large number of convective rainfall events causing intense precipitation over the past few years represents a threat to society, as high-impact storms are generally accompanied by hail, strong winds and lightning, and can lead to flash-floods, particularly in complex orography areas, with dramatic socio-economical consequences. A crucial aspect in nowcasting convective precipitation events is the assessment of their potential in terms of rainfall severity, aimed at providing means to prevent false alarms, which also have socio-economic impacts e.g., on the aviation industry as well as agriculture, transport and public safety. This area of study is very attractive for the scientific community and to the present there is still need for further investigation.

Large efforts are devoted to the study of these phenomena and to the improvement of nowcasting (i.e., 0-6 $\mathrm{h}$ forecasting) [1] to accurately predict the time and location of the occurrence of such convective storms, thus providing an early warning tool to reduce socio-economical impacts. A wide plethora of nowcasting methods exists in literature, based on satellite and radar observations or products [2-16]. Generally, these methods rely on different approaches, ranging from statistical to physical ones [17]. The former are generally based on the projection in time and space of the current state of the weather event: the projection is typically derived by means of atmospheric wind vectors or by comparing similar features observed in previous satellite data images [18]. On the other hand, physical approaches based on Numerical Weather Prediction (NWP) models account for convective and microphysical processes as well as dissipative mechanisms [19]; their ability to perform nowcasting is however limited by the horizontal resolution, high computational cost and the non-perfect knowledge of the initial state. Overall NWP methods are typically outperformed by extrapolation techniques in the first few hours of the forecast [20], while becoming competitive at subsequent forecast times. It has also been demonstrated that assimilation with real-time satellite and radar observations can improve NWP performances, thus improving their nowcasting skills in the first hours of the prediction [21-23]. Parallel to this, satellite observations have also been proven as excellent predictors for convective initiation (i.e., the first occurrence of a $\geq 35 \mathrm{dBZ}$ radar echo) [2,24-32], showing longer lead time compared to radar echoes, which seem to be relevant only when precipitation has already started. Blending techniques are also widespread [33-37], exploiting the advantages of each of the above methods, depending on the time horizon of the forecast as well as the availability of satellite or radar observational data.

A typical limitation of nowcasting methods is the accuracy in predicting precipitation severity, i.e., the ability to distinguish convective events leading to high rainfall from those causing light precipitation. Recent works deal with this essential aspect by studying the correlation of convective storm initial features with its subsequent severity [38,39]. The scope of this work is indeed to gain more insight into the relation between early-stage convective signatures and the following level of precipitation severity. We investigate ways to assess the potential severity of convective precipitation events, by identifying indicators that provide information on this aspect and assist conventional nowcasting tools. To this aim, we perform the analysis of relevant satellite InfraRed (IR) fields (largely discussed in literature $[27,28]$ ) on a dataset of convective precipitation cases leading to severe and nonsevere rainfall, collected over the Italian territory in the period of June-September between 2016 and 2019. Thermal IR fields are derived from observations with the Rapid Scan (RS) Spinning Enhanced Visible and Infrared Imager (SEVIRI) aboard Meteosat Second Generation (MSG) satellite platforms. We show that commonly used IR convective initiation predictors offer relevant information on the future development of the precipitation. Hereafter, the terms predictor, proxy and indicator are used as synonyms to indicate those variables providing ahead-of-time relevant information on subsequent features of the precipitation. The rationale for this work is as follows: we aim to (i) identify a subset of IR indicators-within the wide literature on convective initiation satellite-based proxies (see e.g., [27])—showing distinctive signatures or patterns in the case that convection leads to a hourly cumulative rain greater than $30 \mathrm{~mm}$, as opposed to convective events that only cause less than $10 \mathrm{~mm}$; (ii) show that the spatial extent of the cumuli is, on average, relatively smaller in the case 
of nonsevere precipitation; (iii) derive tentative thresholds for every indicator, and propose an ideal proxy combination to maximize the predictive skill for the severity of the precipitation. The research discussed here is along the lines of previous works (see e.g., [40-42]), similar in spirit but different in both the approach and dataset criteria; we do not use storm-tracking methods but fully characterize the storm features via a static approach by investigating the temporal evolution of relevant IR fields for separate groups of pixels within the area surrounding the storm evolution. The criteria used to design the dataset are peculiar, since we have selected cases where both storm development and subsequent rainfall occurs in the same area (i.e., convective and orographic nature); we do not use the rainfall intensity data, but base our dataset choice on the simultaneous presence of convective initiation and a cumulative hourly rainfall exceeding $30 \mathrm{~mm}$ for severe cases (or smaller than $10 \mathrm{~mm}$ for nonsevere cases), according to the Italian Radar Network. Importantly, this work does not intend to provide a nowcasting tool nor algorithm validation. Overall, the added value of this research is to shed light on the relation between early infrared signatures of the storms and their potential severity in terms of cumulated rainfall, and to specifically test the predictive skill of convective initiation IR satellite field indicators for nowcasting future precipitation severity, on a unique dataset consisting of convective and orographic induced events, thus providing new knowledge that could be incorporated in nowcasting methods. The paper is organized as follows: in Section 2 we first outline the criteria used to collect the dataset (Section 2.1) and then describe the approach adopted to investigate the infrared fields time series (Section 2.2). We then present the results in Section 3, and further discuss the achievements of this analysis. Section 4 draws conclusions and also indicates paths for future work.

\section{Materials and Methods}

In this section, we describe the details of the procedure, criteria and data source products used to collect both convective storms associated with weak and severe precipitation (Section 2.1), and the methodology to analyze the relevant infrared fields for all datasets (Section 2.2).

\subsection{Dataset Collection Criteria}

The analysis presented in this work is conducted on a dataset consisting of convective events leading to severe and nonsevere rainfall. The classification between severe and nonsevere rainfall is based on two references: while [43] classifies rainfall into slight to moderate $(<10 \mathrm{~mm} / \mathrm{h})$, heavy $(>10 \mathrm{~mm} / \mathrm{h})$, and violent $(>50 \mathrm{~mm} / \mathrm{h})$, [44] classifies rainfall into slight to moderate $<10 \mathrm{~mm} / \mathrm{h}$ and cloudburst $(>30 \mathrm{~mm} / \mathrm{h})$. To keep the two classes well distinct, we adopt the following classification: nonsevere $(<10 \mathrm{~mm} / \mathrm{h})$ and severe $(>30 \mathrm{~mm} / \mathrm{h})$. The collected events happened over the Italian peninsula, whose complex orography and coastline proximity make these events both likely to occur and to cause flooding.

Tables 1 and 2 report the detail of the temporal and spatial attributes for 48 severe and 44 weak precipitation events selected over June-September in the period 2016-2019 [45], when high temperature and moisture create the ideal conditions for convection triggering.

The location of the selected severe and nonsevere precipitation cases is reported in Figure 1, which reveals a fairly uniform distribution over the Italian territory $[46,47]$. The data source used to collect the sample relies on the National Radar Network products, provided at $1 \mathrm{~km}$ spatial resolution. In particular, we have used the Vertical Maximum Intensity (VMI) and Surface Rain Total (SRT) variables as the source for our predictand, i.e., the occurrence of convection and rainfall, respectively [48,49]. VMI greater than $35 \mathrm{dBZ}$ echo intensity is associated to regions with convection (for both type of events) [2,24]; shortly after the beginning of convection, the SRT hourly accumulated is used to distinguish between severe (rainfall $>30 \mathrm{~mm}$ ) and nonsevere (rainfall $\lesssim 10 \mathrm{~mm}$ ) cases, respectively (see reference hour in Tables 1 and 2). This criterion is used here to select cases belonging to very distinct rainfall categories, in order to enhance possible differences in the early convection indicators signatures. 
Table 1. Severe precipitation events date (left), peak cumulated rainfall hour (central) and position (right).

\begin{tabular}{|c|c|c|}
\hline Date & Time [UTC] & (Lat,Lon) $\left[{ }^{\circ} \mathbf{N},{ }^{\circ} \mathrm{E}\right]$ \\
\hline 23 June 2016 & 12:00-13:00 & $(40.43,16.23)$ \\
\hline 26 June 2016 & $15: 00-16: 00$ & $(44.73,11.41)$ \\
\hline 1 July 2016 & $12: 00-13: 00$ & $(41.79,14.07)$ \\
\hline 1 July 2016 & $16: 00-17: 00$ & $(44.64,11.49)$ \\
\hline 5 July 2016 & 14:00-15:00 & $(44.64,10.06)$ \\
\hline 9 August 2016 & $5: 00-6: 00$ & $(38.73,16.05)$ \\
\hline 2 September 2016 & 14:00-15:00 & $(44.64,9.5)$ \\
\hline 1 June 2017 & 15:00-16:00 & $(44.96,7.78)$ \\
\hline 16 June 2017 & 14:00-15:00 & $(44.41,9.82)$ \\
\hline 17 June 2017 & 12:00-13:00 & $(41.41,14.23)$ \\
\hline 21 June 2017 & 14:00-15:00 & $(41.04,15.21)$ \\
\hline 22 June 2017 & $12: 00-13: 00$ & $(41.59,14.36)$ \\
\hline 23 June 2017 & $14: 00-15: 00$ & $(40.88,15.72)$ \\
\hline 24 June 2017 & 13:00-14:00 & $(46.04,10.24)$ \\
\hline 24 June 2017 & $14: 00-15: 00$ & $(41.42,15.29)$ \\
\hline 24 June 2017 & $15: 00-16: 00$ & $(40.89,15.83)$ \\
\hline 25 June 2017 & 10:00-11:00 & $(45.01,12.14)$ \\
\hline 25 June 2017 & 11:00-12:00 & $(44.64,11.45)$ \\
\hline 26 June 2017 & 13:00-14:00 & $(44.32,10.77)$ \\
\hline 2 July 2017 & 12:00-13:00 & $(42.74,13.76)$ \\
\hline 07 July 2017 & 13:00-14:00 & $(46.34,12.96)$ \\
\hline 15 July 2017 & 13:00-14:00 & $(41.5,13.83)$ \\
\hline 2 August 2017 & $15: 00-16: 00$ & $(46.48,12.76)$ \\
\hline 7 August 2017 & $12: 00-13: 00$ & $(39.98,16.33)$ \\
\hline 7 August 2017 & $15: 00-16: 00$ & $(39.30,16.54)$ \\
\hline 8 August 2017 & $14: 00-15: 00$ & $(37.73,15.02)$ \\
\hline 8 August 2017 & 14:00-15:00 & $(37.80,14.67)$ \\
\hline 8 August 2017 & 14:00-15:00 & $(39.30,16.54)$ \\
\hline 28 August 2017 & $15: 00-16: 00$ & $(41.66,14.14)$ \\
\hline 29 August 2017 & 13:00-14:00 & $(38.94,16.83)$ \\
\hline 2 June 2018 & $11: 00-12: 00$ & $(40.70,17.11)$ \\
\hline 22 June 2018 & $11: 00-12: 00$ & $(37.80,14.85)$ \\
\hline 23 June 2018 & $15: 00-16: 00$ & $(39.85,9.35)$ \\
\hline 3 August 2018 & 11:00-12:00 & $(36.92,14.84)$ \\
\hline 3 August 2018 & 11:00-12:00 & $(42.05,14.24)$ \\
\hline 3 August 2018 & 11:00-12:00 & $(43.91,7.65)$ \\
\hline 9 August 2018 & 11:00-12:00 & $(41.10,16.23)$ \\
\hline 9 August 2018 & 11:00-12:00 & $(44.68,8.38)$ \\
\hline 9 August 2018 & $12: 00-13: 00$ & $(44.78,12.06)$ \\
\hline 9 August 2018 & 13:00-14:00 & $(37.03,14.82)$ \\
\hline 19 August 2018 & 11:00-12:00 & $(41.69,15.77)$ \\
\hline 01 June 2019 & 11:00-12:00 & $(40.19,18.14)$ \\
\hline 04 June 2019 & 12:00-13:00 & $(43.92,11.98)$ \\
\hline 08 June 2019 & 12:00-13:00 & $(37.46,14.68)$ \\
\hline 18 June 2019 & 12:00-13:00 & $(40.73,16.38)$ \\
\hline 04 July 2019 & 11:00-12:00 & $(41.73,15.89)$ \\
\hline 04 July 2019 & 11:00-12:00 & $(40.68,15.96)$ \\
\hline 26 August 2019 & 10:00-11:00 & $(37.19,14.84)$ \\
\hline
\end{tabular}


Table 2. Nonsevere precipitation events date (left), peak cumulated rainfall hour (central) and position (right).

\begin{tabular}{ccc}
\hline Date & Time [UTC] & (Lat,Lon) $\left[{ }^{\circ} \mathbf{N}^{\circ}{ }^{\circ}\right.$ E] \\
\hline 7 June 2016 & $11: 00-12: 00$ & $(41.52,15.79)$ \\
28 June 2016 & $5: 00-6: 00$ & $(42.39,14.27)$ \\
1 July 2016 & $15: 00-16: 00$ & $(40.09,9.43)$ \\
2 July 2016 & $14: 00-15: 00$ & $(39.97,9.57)$ \\
3 July 2016 & $11: 00-12: 00$ & $(37.61,15.01)$ \\
4 July 2016 & $10: 00-11: 00$ & $(38.09,15.73)$ \\
7 July 2016 & $13: 00-14: 00$ & $(43.20,11.01)$ \\
9 July 2016 & $17: 00-18: 00$ & $(40.40,16.45)$ \\
11 July 2016 & $12: 00-13: 00$ & $(38.09,15.94)$ \\
12 July 2016 & $13: 00-14: 00$ & $(40.90,16.47)$ \\
30 July 2016 & $16: 00-17: 00$ & $(41.13,15.29)$ \\
31 July 2016 & $16: 00-17: 00$ & $(40.19,16.13)$ \\
1 August 2016 & $12: 00-13: 00$ & $(40.65,16.70)$ \\
2 August 2016 & $13: 00-14: 00$ & $(41.61,12.93)$ \\
4 August 2016 & $14: 00-15: 00$ & $(41.86,12.86)$ \\
6 August 2016 & $14: 00-15: 00$ & $(37.91,13.75)$ \\
6 August 2016 & $15: 00-16: 00$ & $(37.95,14.08)$ \\
10 August 2016 & $15: 00-16: 00$ & $(44.32,12.07)$ \\
1 June 2017 & $14: 00-15: 00$ & $(40.84,9.13)$ \\
1 June 2017 & $16: 00-17: 00$ & $(40.42,9.35)$ \\
3 June 2017 & $12: 00-13: 00$ & $(41.37,14.68)$ \\
7 June 2017 & $14: 00-15: 00$ & $(37.33,14.14)$ \\
4 July 2017 & $17: 00-18: 00$ & $(45.15,7.13)$ \\
13 July 2017 & $8: 00-9: 00$ & $(46.19,12.91)$ \\
13 July 2017 & $10: 00-11: 00$ & $(45.33,11.72)$ \\
21 July 2017 & $15: 00-16: 00$ & $(40.31,16.11)$ \\
04 August 2017 & $16: 00-17: 00$ & $(40.80,15.27)$ \\
05 August 2017 & $14: 00-15: 00$ & $(40.15,15.91)$ \\
08 August 2017 & $14: 00-15: 00$ & $(40.14,9.54)$ \\
16 June 2018 & $11: 00-12: 00$ & $(41.30,16.03)$ \\
16 June 2018 & $13: 00-14: 00$ & $(40.89,16.54)$ \\
18 June 2018 & $13: 00-14: 00$ & $(40.29,8.83)$ \\
19 June 2018 & $15: 00-16: 00$ & $(39.94,15.99)$ \\
03 July 2018 & $13: 00-14: 00$ & $(41.86,15.56)$ \\
10 August 2018 & $12: 00-13: 00$ & $(38.42,16.34)$ \\
10 August 2018 & $14: 00-15: 00$ & $(39.45,9.40)$ \\
22 September 2018 & $14: 00-15: 00$ & $(41.93,14.35)$ \\
01 June 2019 & $11: 00-12: 00$ & $(42.65,13.26)$ \\
10 June 2019 & $13: 00-14: 00$ & $(37.57,14.34)$ \\
06 July 2019 & $14: 00-15: 00$ & $(40.19,16.24)$ \\
20 July 2019 & $14: 00-15: 00$ & $(43.20,11.13)$ \\
01 August 2019 & $15: 00-16: 00$ & $(46.67,11.41)$ \\
06 August 2019 5eptember 2019 & $15: 00-16: 00$ & $(40.63,9.28)$ \\
\hline & & $(41.70,12.78)$ \\
\hline
\end{tabular}




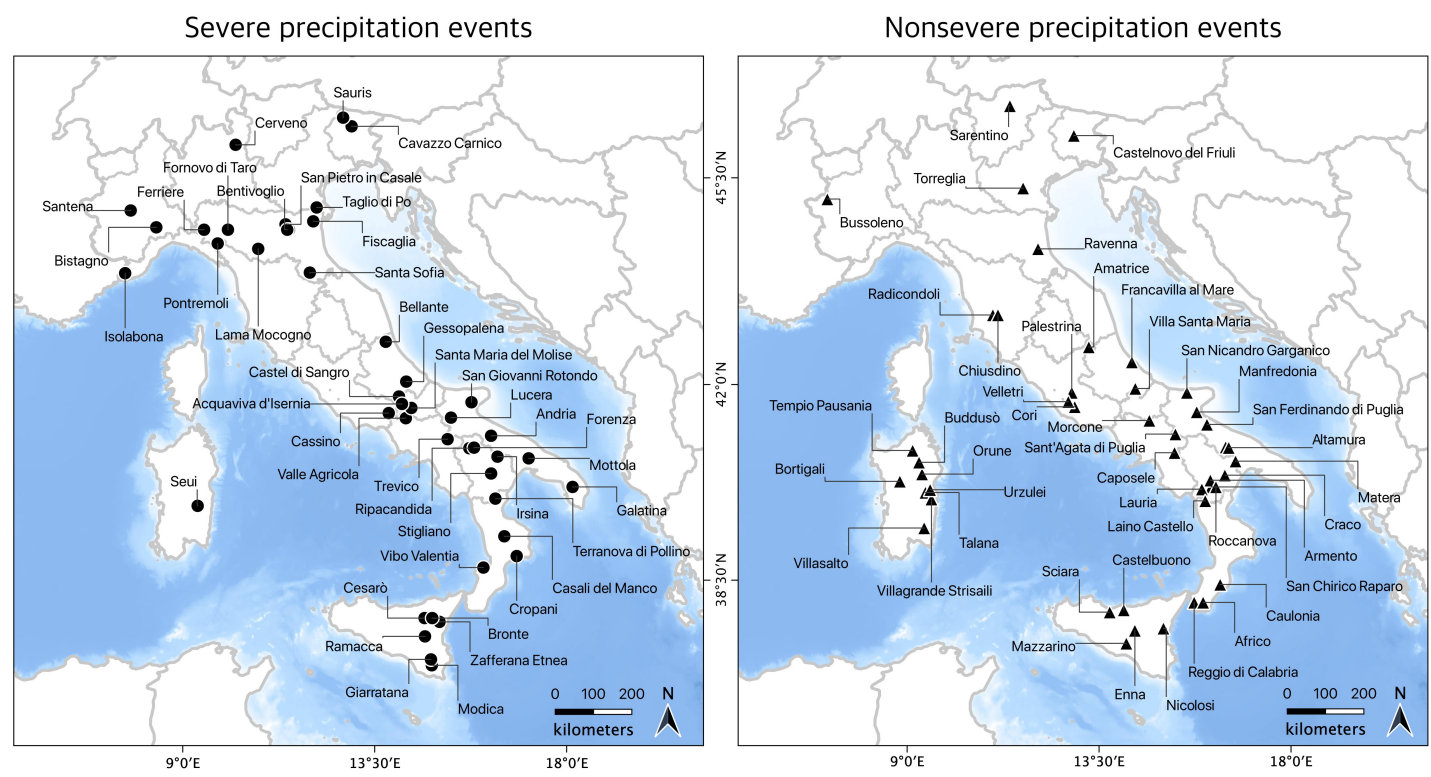

Figure 1. Spatial distribution for the collected severe (circles) and nonsevere (triangles) precipitation events.

Figure 2 shows representative severe and nonsevere precipitation cases where both VMI and SRT radar layers are reported $\left(1 \times 1 \mathrm{~km}^{2}\right.$ grid resolution); the values for VMI and SRT are consistent with the above requirements. Figure 2 also reports the SEVIRI grid, which will be used in the analysis, as explained in Section 2.2. It should be noticed that both convection and rainfall occur roughly within the same area and the event is quite localized; moreover the time of rainfall peak (see Tables 1 and 2) is not anticipated by light long-lasting rain. We have also carried out visual inspection of each case to ensure that selected events are localized, non-advective, and mostly feature clear surrounding conditions. Such features make these events well-suited for a static analysis approach (see Section 2.2), without using a sophisticated tracking methodology; in addition, the typical sudden growth of a cumulus occurs, spreading out in the surrounding area, which is typical of such convective precipitation events. We should stress that the criteria described above for the design of the severe and weak precipitation dataset are very peculiar. These events are classified as brief and localized (according to the classification in [50]) since they are short-lived (i.e., last less than $12 \mathrm{~h}$ ) and feature small spatial extent (i.e., less than $50 \times 50 \mathrm{~km}^{2}$ ). While the case studies selected in this work fall into this classification, they actually feature a much lower spatio-temporal extent than the above limit $(\sim 3-4$ h).

\subsection{Static Approach}

Let us now describe the method used to study the observables of interest for the collected dataset. In particular, we have proceeded to the analysis of infrared fields derived by the SEVIRI rapid scan aboard MSG platforms. This provides radiometric measurements in the Visible $(0.6,0.8 \mu \mathrm{m})$, Near Infrared $(1.6 \mu \mathrm{m})$ and Infrared $(3.9,6.2,7.3,8.7,9.7,10.8,12.0,13.4 \mu \mathrm{m})$ spectral range at $5 \mathrm{~min}$ intervals over Europe and North Africa (covering a latitude range from approximately $15^{\circ}$ to $70^{\circ} \mathrm{N}$ ), with $3 \times 3 \mathrm{~km}^{2}$ spatial resolution at nadir (for further details and specifications of the instrument see [51]. Such a high scan frequency proves to be crucial in this context, since the typical evolution of convective precipitation events is on the order of tens of minutes. In fact, these events are hard to forecast with sufficient accuracy solely with NWP methods, and need real-time observational support. The infrared fields considered here are largely discussed in the scientific literature, and have been demonstrated to be robust indicators for nowcasting early convection stages. 
Severe precipitation event 4 July 2019
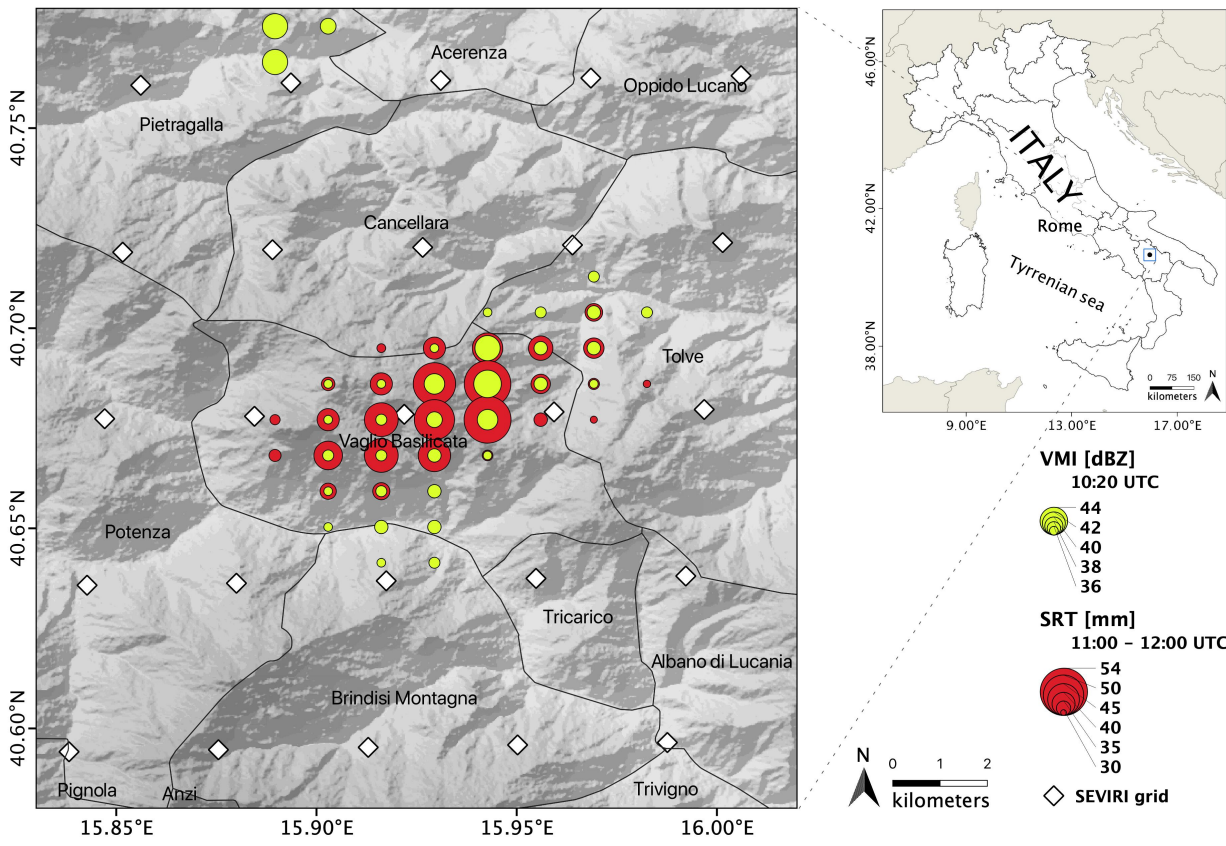

(a)

\section{Nonsevere precipitation event 11 July 2016}
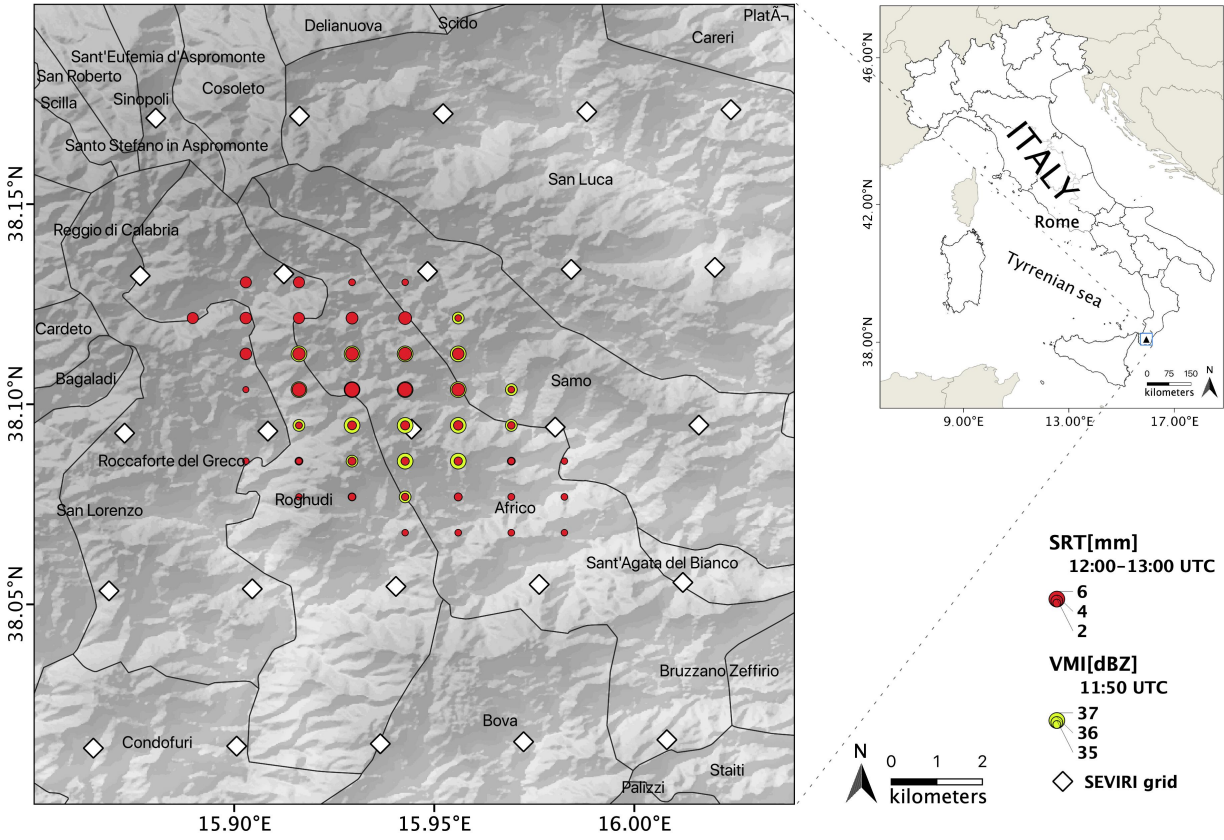

(b)

Figure 2. Severe (a) and nonsevere (b) storm examples on 4 July 2019 and 11 July 2016, with Surface Rain Total (SRT, red) values $>30 \mathrm{~mm}$ and $\lesssim 10 \mathrm{~mm}$, respectively. Virtual Maximum Intensity (VMI, yellow) values higher than $35 \mathrm{dBZ}$ echo intensity indicate convection occurs in both cases (Source: [45]). The SEVIRI $5 \times 5$ gridded box (white diamonds) is also reported. Severe case (a) is located in Basilicata near Potenza, whereas the nonsevere case $(\mathbf{b})$ is in Calabria, near Reggio Calabria. 
Table 3 reports the indicators considered in this work: these are divided into three groups, according to the classification in [27] based on the storm physical properties described, namely growth, glaciation and updraft strength. In fact, each proxy is either a channel difference or its corresponding temporal gradient, whose physical interpretation is based on the weighting functions associated with the MSG channels. Brightness temperatures relative to each channel tend to decrease when growing cumuli approach high levels in the troposphere, and accordingly, differences among channels tend to zero (saturation). For example, proxy $\mathrm{P}_{1}$ in Table $3(6.2-10.8 \mu \mathrm{m})$ is expected to progressively become higher and closer to zero as cumuli grow up to the tropopause. It is then implied that the updraft strength of the growing cumuli can be extracted from the rate of change of the $10.8 \mu \mathrm{m}$ brightness temperature as well as other channel differences (e.g., [52,53]).

Table 3. Infrared Field Indicators (classification is based on the storm physical properties [27]).

\begin{tabular}{ll}
\hline Class & Proxy $\left(\mathbf{P}_{\mathbf{1}}, \mathbf{P}_{\mathbf{2}}, \ldots, \mathbf{P}_{\mathbf{1 8}}\right)$ \\
\hline Cloud Depth & \\
$\mathrm{P}_{1}$ & $6.2-10.8 \mu \mathrm{m}$ \\
$\mathrm{P}_{2}$ & $6.2-7.3 \mu \mathrm{m}$ \\
$\mathrm{P}_{3}$ & $7.3-13.4 \mu \mathrm{m}$ \\
$\mathrm{P}_{4}$ & $6.2-9.7 \mu \mathrm{m}$ \\
$\mathrm{P}_{5}$ & $8.7-12 \mu \mathrm{m}$ \\
\hline $\mathrm{Glaciation}$ & \\
$\mathrm{P}_{6}$ & 5.7-10.8 $\mu \mathrm{m}$ \\
$\mathrm{P}_{7}$ & 5-min trend: $8.7-10.8 \mu \mathrm{m}$ \\
$\mathrm{P}_{8}$ & 5-min trend: $(8.7-10.8)-(10.8-12) \mu \mathrm{m}$ \\
$\mathrm{P}_{9}$ & 12-10.8 $\mu \mathrm{m}$ \\
$\mathrm{P}_{10}$ & 5-min trend: $12-10.8 \mu \mathrm{m}$ \\
$\mathrm{P}_{11}$ & \\
\hline $\mathrm{Updraft} \mathrm{Strength}_{12}$ & 5-min trend: $6.2-7.3 \mu \mathrm{m}$ \\
$\mathrm{P}_{12}$ & 15-min trend: $10.8 \mu \mathrm{m}$ \\
$\mathrm{P}_{13}$ & 10-min trend: $10.8 \mu \mathrm{m}$ \\
$\mathrm{P}_{14}$ & 5-min trend: $10.8 \mu \mathrm{m}$ \\
$\mathrm{P}_{15}$ & 5-min trend: $6.2-10.8 \mu \mathrm{m}$ \\
$\mathrm{P}_{16}$ & 5-min trend: $6.2-12 \mu \mathrm{m}$ \\
$\mathrm{P}_{17}$ & 5-min trend: $9.7-13.4 \mu \mathrm{m}$ \\
$\mathrm{P}_{18}$ &
\end{tabular}

In order to study the infrared properties of each convective precipitation event and its surrounding area, we have selected a $5 \times 5$ SEVIRI pixel-box, centered on the radar pixel identified as the center of the event, i.e., where the reference peak of cumulated hourly rainfall occurs. This size of the box has been chosen to account for different storm spatial extensions (up to the largest one) and to study the evolution stages roughly until maximum expansion. Other works use different box sizes [40], ranging from $3 \times 3$ to $51 \times 51$ pixels, depending on the scale of interest. We have found this size is the optimal trade-off fitting the purpose of the study, i.e., to investigate the immediate area near the central pixel close to the maximum peak rainfall. Potential sources of error due to parallax effect could account for a pixel shift in the North-South direction. All information about the early stage of storms is fully contained inside the box, as the pixels surrounding the box do not show brightness temperature values typical of storm presence. The selected case studies consist of non-advective storms, where both convection and rainfall occur roughly within the same area, hence a static approach is appropriate for the purpose of the analysis. Given the $5 \times 5$ gridded box, we then investigate the time series of relevant infrared fields for each pixel within the box. The grid box size is large enough to contain information both in the area of the storm core as well as in the neighbour pixels where the effects of the storm are only minor. To take this into account we have therefore carried out the analysis separately for different clusters of pixels, namely: (1) all pixels in the box, (2) only those near the maximum rainfall peak region, (3) pixels with $\mathrm{T}_{\mathrm{B}}<240 \mathrm{~K}$ (widely used threshold to detect convective 
systems, e.g., [54]) and finally (4) the ones exhibiting the lowest brightness temperature at $10.8 \mu \mathrm{m}$ within the reference hour (see Tables 1 and 2). This will help us differentiate the dynamical behaviour near the core of the storm from the outer regions of the box. Furthermore, a common time frame (similarly to [41]) is used in the study, in order to ensure synchronization among the dynamics over all SEVIRI pixels from all cases (both severe and nonsevere). This is achieved by investigating the trend of each indicator for every pixel as a function of a common relative time coordinate $\left(t_{\text {rel }}=t-t_{\min , 10.8 \mu \mathrm{m}}\right)$, where $t_{\min , 10.8 \mu \mathrm{m}}$ refers to the time when the brightness temperature at $10.8 \mu \mathrm{m}$ reaches its lowest value over that pixel. Such a method allows for a meaningful comparison between the dynamics over different pixels, whereby trend indicators are compared at equivalent times up to $2.5 \mathrm{~h}$ before and after $t_{\text {rel }}=0$. We therefore decided to compute the time series of the indicators by averaging their observed values separately over severe and nonsevere precipitation cases (and for different clusters of pixels within the box) through standard mean:

$$
\overline{\mathrm{P}}_{\mathrm{i}, \mathrm{j}}=\left[\left(\sum_{\text {events }} \sum_{\text {pix }} \mathrm{P}_{\mathrm{i}}\left(\mathrm{t}_{\mathrm{j}}\right)\right) /\left(\mathrm{N}_{\text {pix }} \mathrm{N}_{\text {events }}\right)\right]
$$

where $i$ refers to the proxy number (see Table 3 ) and $j$ indicates the time $t_{j}$ when the mean value is computed. Besides, the index events runs over the number $\mathrm{N}_{\text {events }}$ of severe or nonsevere cases, whereas pix indicates the considered type of pixels of size $\mathrm{N}_{\text {pix }}$. It may also be useful to compare temporal averages of the above quantity (e.g., on $30 \mathrm{~min}$ intervals), so to smooth time differences between the events:

$$
\overline{\bar{P}}_{i}=\left(\sum_{j} \overline{\mathrm{P}}_{i, j}\right) /\left(t_{n}\right)
$$

where $j$ runs over the single time interval $t_{n}$, taken as $30 \mathrm{~min}$ in our analysis, hence including seven samples of $5 \mathrm{~min}$ SEVIRI Rapid Scans. Standard deviation is also computed:

$$
\sigma_{\mathrm{i}}\left(\mathrm{t}_{\mathrm{n}}\right)=\sqrt{\frac{\sum_{\mathrm{j}}\left(\overline{\mathrm{P}}_{\mathrm{i}, \mathrm{j}}-\overline{\overline{\mathrm{P}}}_{\mathrm{i}}\right)^{2}}{\mathrm{t}_{\mathrm{n}}-1}} .
$$

The following section analyzes the trend of each indicator using the statistics introduced above [55].

\section{Results and Discussion}

This section presents the temporal variation of the indicators reported in Table 3 around the time of the precipitation occurrence. Then we attempt to single out the main proxies carrying information on the subsequent convective precipitation severity level, and derive tentative thresholds to distinguish between the two classes of events. As mentioned above, the indicators investigated here (see Table 3) are generally used as convective initiation stand-alone predictors with a typical lead time of the order of tens of minutes. In this context, we investigate whether this still holds up for the selected dataset (which features a convective initial stage in all samples), and further explore the potential of these indicators to predict the severity level of the storms. For proxies related to the severity of the precipitation, we expect to take on distinctive pattern trends or different values depending on the severity level discussed above (i.e., accumulated hourly rainfall $>30 \mathrm{~mm}$ or $\lesssim 10 \mathrm{~mm}$ ). Indeed, we find that some of the proxies in Table 3 do carry information about the future evolution of the precipitation, and are potentially able to distinguish between convective events leading to severe and nonsevere rainfall. For the sake of conciseness, we report here only the infrared fields identified as the best candidates by means of criteria we explain below. Figure 3 shows the temporal variation (i.e., time series) of indicators $\mathrm{P}_{1}, \mathrm{P}_{2}, \mathrm{P}_{4}, \mathrm{P}_{6}, \mathrm{P}_{8}$ (from Table 3 ) up to $2.5 \mathrm{~h}$ around the time origin $\mathrm{t}_{\text {rel }}=0$. This is the relative time when-for each pixel of the box-the $10.8 \mu \mathrm{m}$ brightness temperature reaches its lowest value within the reference hour of the event. Both severe and nonsevere precipitation cases are shown. 
The variation is shown in terms of both the instantaneous values (based on Equation (1), i.e., mean over events only) and the average over $30 \mathrm{~min}$ time intervals (based on Equation (2)) prior to the event.

As mentioned above, the SEVIRI box was chosen to contain the storm region as well as pixels away from it. To account for this, we have performed a separate analysis for distinct clusters of pixels within the box, which allows us to highlight crucial information on the average features of the storm core as opposed to less perturbed nearby regions in the box. This is particularly interesting if we compare the analysis including all pixels (black line) to the one where only 'cold' pixels are considered (green line), i.e., those where $\mathrm{T}_{\mathrm{B}}$ at $10.8 \mu \mathrm{m}$ reach values smaller than $240 \mathrm{~K}$ within the reference peak hour. This comparison reveals smaller differences for severe precipitation cases (solid line) compared to nonsevere ones (dashed line), suggesting on average a relatively limited spatial extent of nonsevere events-in terms of pixels where cumuli reach freezing levels in the troposphere-as opposed to severe events, where most pixels are actually 'cold' ones. This is also supported by a low percentage found on average of 'cold' pixels for nonsevere cases, namely $23 \%$ against $69 \%$ for severe ones. Furthermore, we notice a clear trend of the proxies for both severe and nonsevere precipitation cases, whose values approach zero on average at the time origin; however, mean channel differences for severe cases become higher and closer to zero at the time origin, implying that cumuli on average grow further up in the atmosphere. A sharp peak is present around the time origin for all groups of pixels and both types of events; the trend pattern inverts afterwards demonstrating that precipitation events have actually passed the mature phase and started fading. This peak is a clear sign that dynamics are well separated before and after this point, supporting the choice of a synchronized time reference.

Since we are interested in the early stage prior to the peak time, $30 \mathrm{~min}$ temporal averages are shown in Figure 3 only up to $2.5 \mathrm{~h}$ before the peak. The intent here is to investigate how long before the peak time, a net average difference persists between proxy values for severe and weak precipitation cases. We find that this is relatively higher for proxies $\mathrm{P}_{1}, \mathrm{P}_{2}, \mathrm{P}_{4}$ (on the order of few degrees) compared to the others $(\sim 1 \mathrm{~K})$; besides, for all indicators, the separation between mean values of severe and nonsevere precipitation cases decreases for $t_{\text {rel }}<-1 \mathrm{~h}$. We can, therefore, argue that only within the hour before the peak time there is potential for the distinction between the two classes. This is somewhat expected, since convective precipitation events arise and evolve on short time scales, and convective initiation fields are valid predictors only a few tens of minutes before the event occurrence. Nonetheless it is useful to check the analysis up to $2.5 \mathrm{~h}$ before, as to provide a reference showing for both classes of events that proxy values are roughly similar on average in clear conditions, but then evolve differently near the peak time. Importantly, the method to choose the best candidate predictors (out of the ones reported in Table 3 ) is related to the standard deviations extracted with Equation (3) (see vertical bars in Figure 3). The indicators selected as potential predictors are the ones where temporal averages for severe and nonsevere precipitation cases do not overlap up to one standard deviation from the mean, at least in the interval $t_{\text {rel }}=[-1,0] \mathrm{h}$, relative to the analysis on the central pixels and the ones where $T_{B}$ at $10.8 \mu \mathrm{m}$ is lowest within each box. This criterion has been taken for these infrared fields to actually being able to distinguish in a systematic and stable way the two classes of events. Hence, this criterion has led us to narrow the initial number of indicators considered in Table 3 to the six shown in Figure 3 as potentially carrying information on the severity of the precipitation, and hence being valuable predictor candidates. All other proxies have been excluded from the subsequent analysis since they do not fulfil this requirement, and have been deemed to be inadequate to provide early information about the rainfall severity. In fact, we have not found substantial and temporally stable differences for all updraft strength indicators; this seems to suggest that events not leading to strong precipitation appear to have similar strength in the updraft compared to severe ones, at least in terms of these indicators and according to the requirements discussed above. While it is not the scope of this study, we note that values for all proxies from Table 3 are well within the range of acceptable values found in the literature for predicting convective initiation, supporting these indicators as valid stand-alone predictors for early convective stages. 


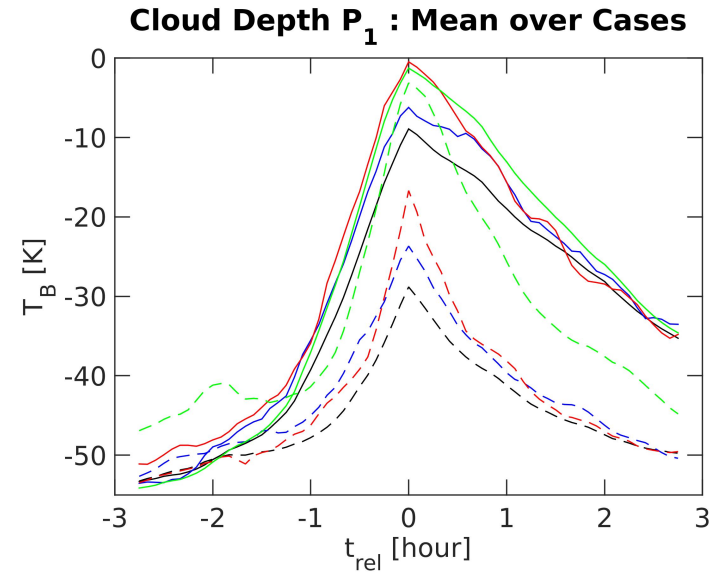

(a)

Cloud Depth $\mathbf{P}_{2}$ : Mean over Cases

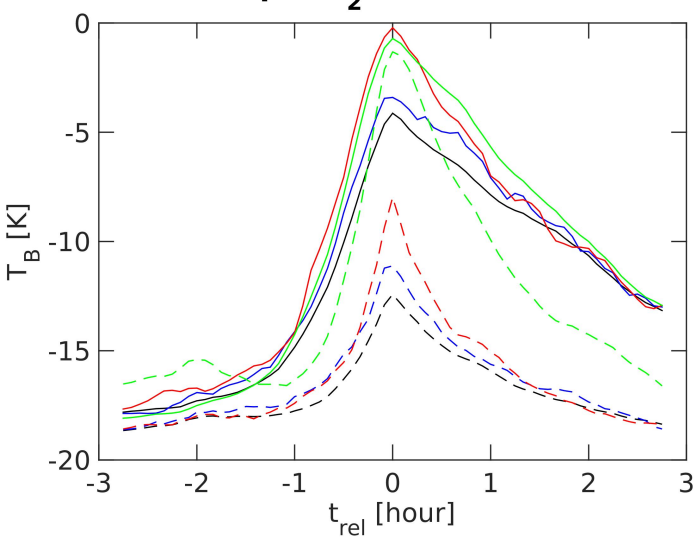

(c)

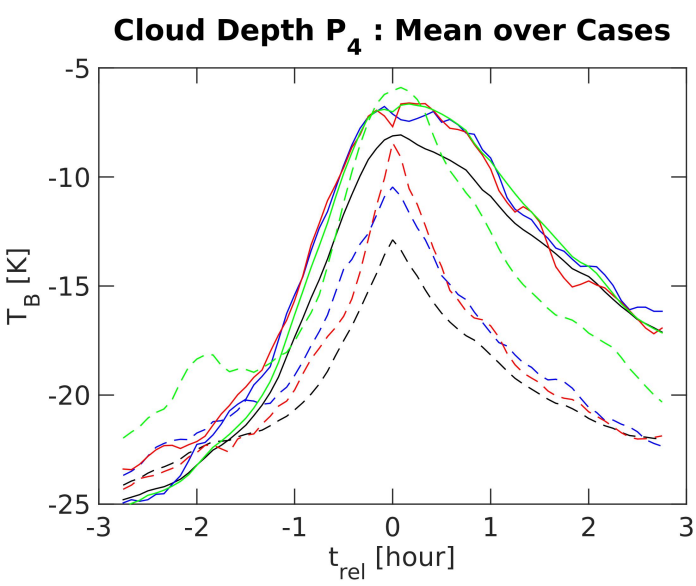

(e)

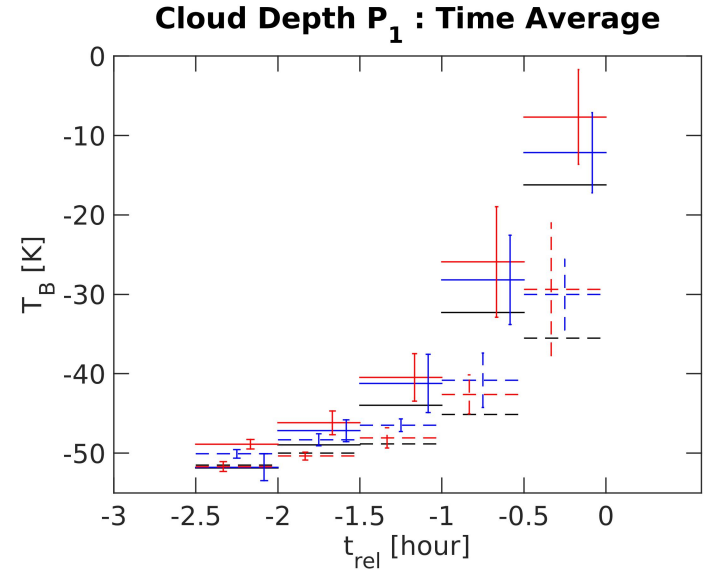

(b)

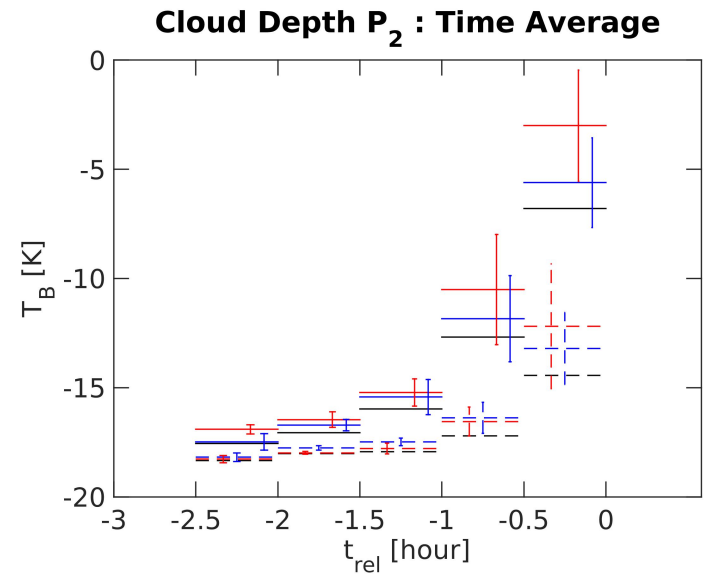

(d)

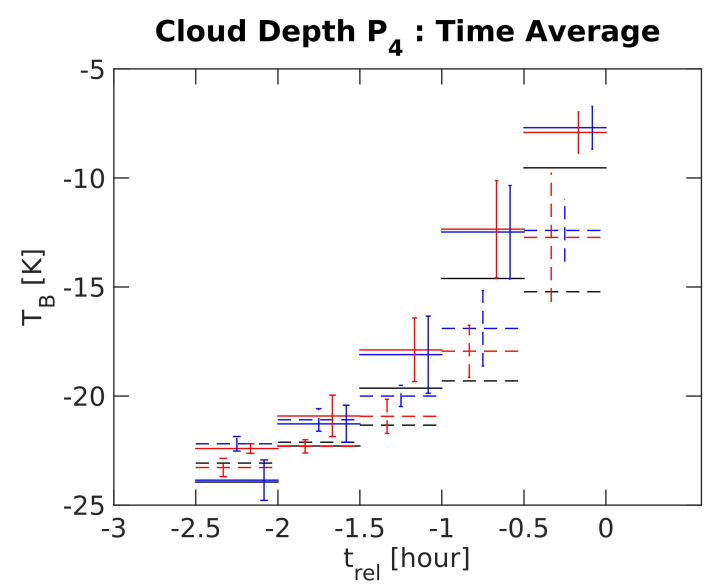

(f)

- Severe: All Pix
- - Nonsevere: All Pix
- Severe: Central Pix
- - Nonsevere: Central Pix
- Severe: $\min \left\{\mathrm{T}_{\mathrm{B}}[10.8 \mu \mathrm{m}]\right\} \mathrm{Pix}$
-- Nonsevere: $\min \left\{\mathrm{T}_{\mathrm{B}}[10.8 \mu \mathrm{m}]\right\} \mathrm{Pix}$
Severe: $\mathrm{T}_{\mathrm{B}}<240 \mathrm{~K} \mathrm{Pix}$
-- Nonsevere: $\mathrm{T}_{\mathrm{B}}<240 \mathrm{~K} \mathrm{Pix}$

Figure 3. Cont. 


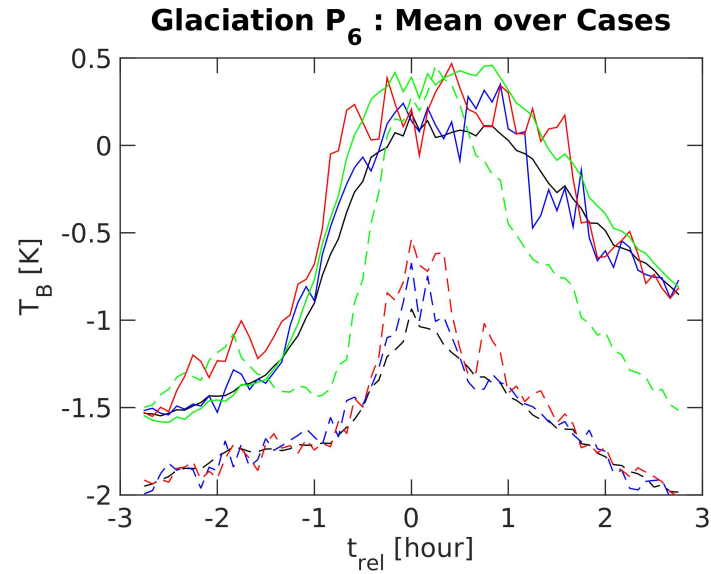

(g)

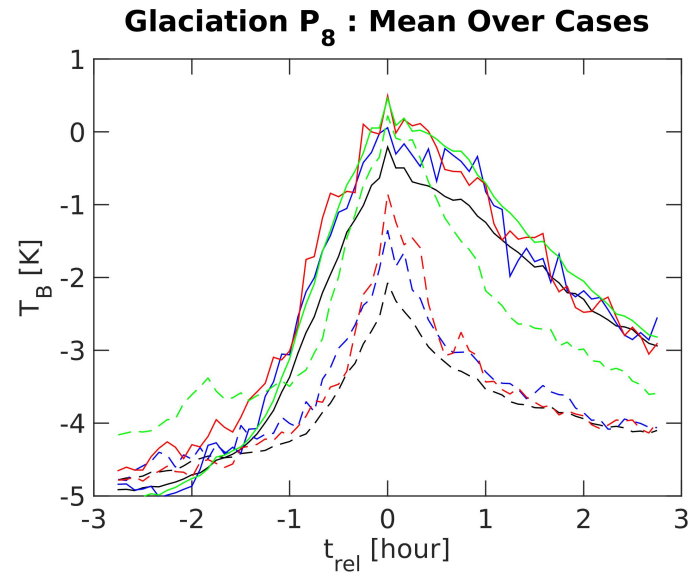

(i)

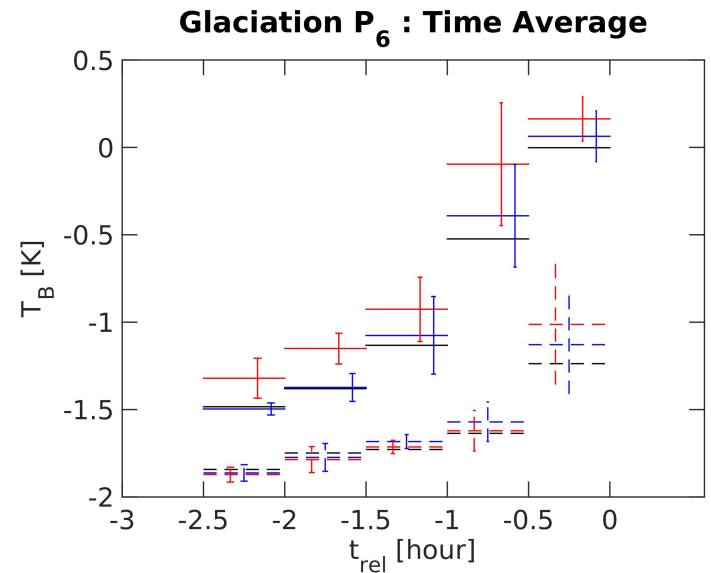

(h)

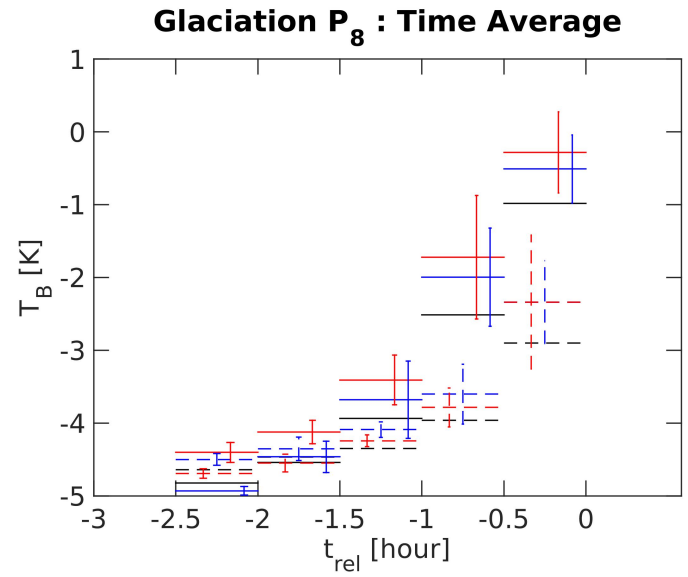

(j)

- Severe: All Pix
- - Nonsevere: All Pix
- Severe: Central Pix
- - Nonsevere: Central Pix
- Severe: $\min \left\{\mathrm{T}_{\mathrm{B}}[10.8 \mu \mathrm{m}]\right\} \mathrm{Pix}$
-- Nonsevere: $\min \left\{\mathrm{T}_{\mathrm{B}}[10.8 \mu \mathrm{m}]\right\} \mathrm{Pix}$
Severe: $\mathrm{T}_{\mathrm{B}}<240 \mathrm{~K} \mathrm{Pix}$
- - Nonsevere: $\mathrm{T}_{\mathrm{B}}<240 \mathrm{~K} \mathrm{Pix}$

Figure 3. Time series of indicators $P_{1}(\mathbf{a}, \mathbf{b}), P_{2}(\mathbf{c}, \mathbf{d}), P_{4}(\mathbf{e}, \mathbf{f}), P_{6}(\mathbf{g}, \mathbf{h})$ and $P_{8}(\mathbf{i}, \mathbf{j})$ from Table 3 for convective events leading to severe (solid line) and nonsevere (dashed line) precipitation. The mean over cases (left column, Equation (1)) and the time average over $30 \mathrm{~min}$ intervals (right column, Equation (2)) up to $2.5 \mathrm{~h}$ before $\mathrm{t}_{\mathrm{rel}}=0$, are computed for separate clusters of pixels within the box, namely all (black), central (blue), lowest brightness temperature at $10.8 \mu \mathrm{m}$ within the reference hour (red) and $\mathrm{T}_{\mathrm{B}}<240 \mathrm{~K}$ (green) pixels. Vertical bars are standard deviation based on Equation (3). Time average for $\mathrm{T}_{\mathrm{B}}<240 \mathrm{~K}$ pixels and standard deviations for all pixels analysis are not necessary in our study, hence these are not shown in the graph.

However, our focus in this work is not on the occurrence of convection, but rather on the predictive potential to distinguish between severe and nonsevere precipitation events. For this reason, we focussed on the selected indicators in Figure 3, and explored further their predictive skill via a simple diagnostic procedure (i.e., no separation between training and test datasets). We are therefore interested in the early stage prior to the peak time, to find early signatures of incoming precipitation events and to maximize the lead warning time to nowcast the event. Hereafter we exclusively deal 
with the pixel in each box reaching the lowest brightness temperature at $10.8 \mu \mathrm{m}$, representing the highest cloud top which is a good indicator for the precipitation intensity. Notice that in some cases (most nonsevere precipitation events) the lowest brightness temperature achieved within the box in the reference peak hour may be higher than $240 \mathrm{~K}$. We have looked into a probability detection scheme, based on simultaneous and interdependent fulfilment of a set of critical threshold conditions on these indicators. It is anticipated that only three indicators were chosen for this scheme, as adding more proxies would make the statistics less accurate. Instead of looking for the best threshold on each proxy separately, we have evaluated the skill of an hypothetical interdependent three-proxy based predictive scheme. This was achieved by searching for the best proxy-thresholds combination that would maximize the difference between the accuracy (ACC) and the probability of false detection (POFD), as this option tends to favour a relative reduction of false alarms, while keeping a reasonable accuracy. We recall the standard expressions for these statistical measures, together with the probability of detection (POD) and BIAS:

$$
\begin{gathered}
\mathrm{ACC}=\frac{\text { Hits }+ \text { Correct Negatives }}{\text { Total Number of Cases }} \\
\text { POD }=\frac{\text { Hits }}{\text { Hits }+ \text { Misses }} \\
\text { POFD }=\frac{\text { False Alarms }}{\text { Correct Negatives + False Alarms }} \\
\text { BIAS }=\frac{\text { Hits }+ \text { False Alarms }}{\text { Hits }+ \text { Misses }}
\end{gathered}
$$

In this work, Hits (Correct Negatives) refers to the number of severe (nonsevere) precipitation cases whose proxy values are simultaneously greater (smaller) than the critical thresholds found on each proxy. Conversely, Misses (False Alarms) denote the difference between the total number of severe (nonsevere) precipitation cases and Hits (Correct Negatives), i.e., the remaining cases that have not fulfilled the above requirement. When searching for the most performant three-proxy combination, we have therefore adopted a strict requirement based on the simultaneous fulfilment of each proxy condition (i.e., giving the same importance level to each predictor). Out of all possible combinations with the above six indicators (only including three of these at a time), the most performant solution yielding the higher difference between ACC and POFD was found to be based on indicators $\mathrm{P}_{1}, \mathrm{P}_{2}, \mathrm{P}_{8}$. Therefore Hits refer to the number of severe precipitation cases fulfiling the following simultaneous conditions on each proxy, i.e., $\left[\mathrm{P}_{1}>\mathrm{Th} \mathrm{h}_{1}\right] \cap\left[\mathrm{P}_{2}>\mathrm{Th}_{2}\right] \cap\left[\mathrm{P}_{8}>\mathrm{Th}_{8}\right]$; conversely, Correct Negatives refer to the number of nonsevere precipitation cases satisfying the above with $<$ replacing $>$. Here, the symbol Th stands for the computed critical thresholds maximizing the difference ACC-POFD. Outcomes for this diagnostic statistical evaluation are reported in Table 4.

Table 4. Threshold values for indicators $\mathrm{P}_{1}\left(\mathrm{Th}_{1}\right), \mathrm{P}_{2}\left(\mathrm{Th}_{2}\right)$ and $\mathrm{P}_{8}\left(\mathrm{Th}_{8}\right)$, together with statistical performances for a three-proxy based predicting scheme, based on accuracy (ACC), probability of detection (POD), probability of false detection (POFD) and BIAS, relative to three $30 \mathrm{~min}$ time intervals prior to $\mathrm{t}_{\mathrm{rel}}=0$.

\begin{tabular}{cccccccc}
\hline Time Range Prior to Storms & $\mathbf{T h}_{\mathbf{1}}[\mathbf{K}]$ & $\mathbf{T h}_{\mathbf{2}}[\mathbf{K}]$ & $\mathbf{T h}_{\mathbf{8}}[\mathbf{K}]$ & $\mathbf{A C C}$. & POFD & POD & BIAS \\
\hline $\mathrm{t}_{\mathrm{rel}}=-[0.5,0] \mathrm{h}$ & -9.48 & -3.54 & -0.68 & 0.60 & 0.26 & 0.48 & 0.72 \\
$\mathrm{t}_{\mathrm{rel}}=-[1,0.5] \mathrm{h}$ & -27.16 & -12.12 & -1.72 & 0.63 & 0.16 & 0.43 & 0.57 \\
$\mathrm{t}_{\mathrm{rel}}=-[1.5,1] \mathrm{h}$ & -40.46 & -15.25 & -3.41 & 0.48 & 0.32 & 0.29 & 0.58 \\
\hline
\end{tabular}

The difference between ACC and POFD is-as expected-higher near the maximum time peak (i.e., within the previous two $30 \mathrm{~min}$ time intervals $t_{\text {rel }}=-[0.5,0] \mathrm{h}$ and $\mathrm{t}_{\mathrm{rel}}=-[1,0.5] \mathrm{h}$ ) while at earlier times $\left(t_{\mathrm{rel}}=-[1.5,1] \mathrm{h}\right)$ it drops significantly, as convection is not yet present and 
discrimination between severe and nonsevere precipitation is pointless at this stage. Time ranges before $t_{\text {rel }}=-1.5 \mathrm{~h}$ have not been included, since proxies distributions of severe and nonsevere precipitation cases overlap within less than a standard deviation (see Figure 3). Table 4 also reports the critical threshold value combination (maximizing the pre-definined statistical criterion) for each of these indicators and for every time interval prior to the peak time. One first observation is that critical thresholds for proxies $\mathrm{P}_{1}, \mathrm{P}_{2}, \mathrm{P}_{8}$ are much closer to the mean proxies values of severe precipitation cases (the reader should compare these values to Figure 3, right column). This is somewhat expected since maximizing ACC-POFD tends to reduce false alarms, at the cost of a lower accuracy in identifying potentially severe precipitation events. Absolute values for the reported statistical performances prove that a clear distinction exists between the early stage $\left(t_{r e l}=-[1.5,1] \mathrm{h}\right)$ prior to maximum time peak-when ACC drops under 0.5 and POFD is higher than 0.3 - and the time range $\left(t_{\text {rel }}=-[1,0] \mathrm{h}\right)$, when ACC actually takes a stable value over 0.6 and POFD goes down to 0.26 and 0.16 . Comparison to other works addressing the focus of this study (e.g., [40]) is not straightforward because of different research designs, dataset features, relative times the statistics is performed and different predictors. This is further limited by the severe/nonsevere classification in this work; moreover, homogeneous standards are lacking in this kind of research and not many works are showing the effects of temporal synchronization. Nonetheless, we have evaluated the comparison against the statistical performance from the related work in [40]; based on our analysis, we find on average a slight improvement in terms of POFD ( 0.25 against 0.38$)$, at the expense of a lower capability to identify severe precipitation events (POD: 0.44 against 0.69), with about the same accuracy (ACC $\sim 0.62$ ). One then could argue whether the given performances make this method sufficiently reliable as a stand-alone predictive scheme to distinguish severe from nonsevere precipitation events. Indeed, we believe this method could be valuable when used in combination with other nowcasting methods to mutually improve robustness and reduce false alarm ratio. Finally, potential sources of errors in this work may be related to satellite-radar grids colocation and satellite parallax due to MSG view azimuth angles. Despite these errors, because of the relatively large sample, the wide box and standard deviation calculations, we believe this uncertainty is fully accounted for, and the bulk storm representative properties relevant for this work have been captured.

\section{Conclusions}

In this work, we perform a study on convective initiation infrared field indicators, in order to evaluate their skill to discriminate convective events evolving in severe precipitation from those causing weak rainfall only. The analyzed proxies consist of linear combinations of passive remote sensing infrared observations (channel differences and time trends) with SEVIRI Rapid Scan aboard MSG geostationary satellites. We collected a dataset of 48 convective severe and 44 convective nonsevere precipitation events over the Italian peninsula in the period June-September between 2016 and 2019. Using National Radar Network data products as a source of predictand, convective severe (non severe) storms are defined in this study as convective events with Virtual Maximum Intensity greater than $35 \mathrm{dBZ}$ echo intensity, and an hourly cumulated Surface Rainfall Total value $>30 \mathrm{~mm}(\lesssim 10 \mathrm{~mm})$. Moreover, events are short-lived and feature a small spatial extent. We use a static approach, whereby a SEVIRI $5 \times 5$ gridded box is centered near the storm peak cumulated rainfall. We investigate the temporal dependence of these indicators up to $2.5 \mathrm{~h}$ around the event peak time (identified as the time when $\mathrm{T}_{\mathrm{B}}[10.8 \mu \mathrm{m}]$ reaches its minimum), separately for different clusters of pixels within the boxes, as to isolate the core area of the storm from less affected regions. We also ensure synchronization among events by introducing a common time frame. As time approaches the event occurrence, we observe a pronounced peak whereby mean proxy values tend to zero, and invert their trend afterwards. We find that out of the initial eighteen indicators, six of them (describing growth and glaciation properties) show unique signatures when events evolve toward severe precipitation. For severe events, these mean proxy values are much closer to zero compared to nonsevere ones. In particular, these indicators feature a larger difference between temporal averages—over $30 \mathrm{~min}$ intervals—of severe and nonsevere 
precipitation events, such that no overlap occurs up to one standard deviation prior to maximum peak. We have selected only those proxies where this difference is systematic at least for two hours before peak time. These are, therefore, deemed to carry crucial information to help discriminate severe from nonsevere precipitation events based on the relative difference between their corresponding mean proxy values. According to the above requirements, updraft strength indicators do not hold significant discrimination signatures instead. Moreover, nonsevere precipitation events are more likely to feature a smaller spatial extent (in terms of cumuli reaching freezing levels in the troposphere) compared to their severe counterpart, as only $23 \%$ of pixels are identified as cold (i.e., $\mathrm{T}_{\mathrm{B}}<240 \mathrm{~K}$ ) compared to $69 \%$ for severe cases.

As a follow-on goal of this study, we have evaluated the potential skill of these indicators as predictors for precipitation level severity. Based on a preliminary diagnostic procedure we have found the best three-proxy-based combination by maximizing the difference between accuracy and probability of false detection, so as to reduce false alarms while keeping relatively high accuracy. Statistical scores show that values for accuracy are relatively high (greater than 0.6) within the hour before peak time, with POFD less than 0.26. In particular, such a POFD is an improvement over previous results though at the expenses of decreased probability of detection. Therefore, we can conclude that some infrared observations do hold significant information to discriminate between severe and nonsevere precipitation events, however with relatively good predictive skill. While we consider these scores not good enough to make this a stand-alone algorithm to distinguish between convective events leading to severe and nonsevere precipitation, we believe it could be a valuable tool to integrate and support other nowcasting methods. To achieve this, in future work we plan to include microwave observations - when available for the selected events-which would potentially increase the confidence level of the prediction. Moreover, we will also further explore alternative ways to define temporal synchronization and time reference, which would support the consideration of these results into an operational forecasting framework. In fact, storm management in the Italian territory could also benefit from this, as the findings of this work may contribute to the improvement of the exact temporal and spatial collocation of the precipitation events (restricting the potential time/area of occurrence), and secondly they could help to limit the false alarms, which are also a typical issue for storm prediction. Given the design of the project, the features used to select the dataset and the approach used in the analysis, this work contributed to shedding light in the correlation between infrared observations prior to convection and precipitation severity level, thus extending previous works in this field.

Author Contributions: D.G., F.R., D.C. and E.R. designed the research, analyzed the data and wrote the paper. M.P.D.N., S.G., F.D.P. collected the dataset and processed the data. E.G., S.T.N., S.L. and M.V. contributed to data processing, analysis and evaluation process. All authors have read and agreed to the published version of the manuscript.

Funding: This research received no external funding.

Conflicts of Interest: The authors declare no conflict of interest. The founding sponsors had no role in the design of the study; in the collection, analyses, or interpretation of data; in the writing of the manuscript, and in the decision to publish the results.

\section{References}

1. Wang, Y.; Coning, E.; Harou, A.; Jacobs, W.; Joe, P.; Nikitina, L.; Roberts, R.; Wang, J.; Wilson, J.; Atencia, A.; et al. Guidelines for Nowcasting Techniques; WMO-No. 11988; World Meteorological Organization: Geneva, Switzerland, 2017; ISBN 978-92-63-11198-2. Available online: https:/ /library.wmo.int/doc_num. php?explnum_id=3795 (accessed on 8 August 2020).

2. Mecikalski, J.R.; Bedka, K.M. Forecasting Convective Initiation by Monitoring the Evolution of Moving Cumulus in Daytime GOES Imagery. Mon. Weather Rev. 2006, 134, 49-78. [CrossRef] 
3. Bedka, K.; Brunner, J.; Dworak, R.; Feltz, W.; Otkin, J.; Greenwald, T. Objective Satellite-Based Detection of Overshooting Tops Using Infrared Window Channel Brightness Temperature Gradients. J. Appl. Meteorol. Climatol. 2010, 49, 181-202. [CrossRef]

4. Sieglaff, J.M.; Hartung, D.C.; Feltz, W.F.; Cronce, L.M.; Lakshmanan, V. A Satellite-Based Convective Cloud Object Tracking and Multipurpose Data Fusion Tool with Application to Developing Convection. J. Atmos. Ocean. Technol. 2013, 30, 510-525. [CrossRef]

5. Cintineo, J.L.; Pavolonis, M.J.; Sieglaff, J.M.; Lindsey, D.T. An Empirical Model for Assessing the Severe Weather Potential of Developing Convection. Weather Forecast. 2014, 29, 639-653. [CrossRef]

6. Bedka, K.M.; Wang, C.; Rogers, R.; Carey, L.D.; Feltz, W.; Kanak, J. Examining Deep Convective Cloud Evolution Using Total Lightning, WSR-88D, and GOES-14 Super Rapid Scan Datasets. Weather Forecast. 2015, 30, 571-590. [CrossRef]

7. Gravelle, C.M.; Mecikalski, J.R.; Line, W.E.; Bedka, K.M.; Petersen, R.A.; Sieglaff, J.M.; Stano, G.T.; Goodman, S.J. Demonstration of a GOES-R Satellite Convective Toolkit to "Bridge the Gap" between Severe Weather Watches and Warnings: An Example from the 20 May 2013 Moore, Oklahoma, Tornado Outbreak. Bull. Am. Meteorol. Soc. 2016, 97, 69-84. [CrossRef]

8. Line, W.E.; Schmit, T.J.; Lindsey, D.T.; Goodman, S.J. Use of Geostationary Super Rapid Scan Satellite Imagery by the Storm Prediction Center. Weather Forecast. 2016, 31, 483-494. [CrossRef]

9. Mecikalski, J.R.; Jewett, C.P.; Apke, J.M.; Carey, L.D. Analysis of Cumulus Cloud Updrafts as Observed with 1-Min Resolution Super Rapid Scan GOES Imagery. Mon. Weather Rev. 2016, 144, 811-830. [CrossRef]

10. Dixon, M.; Wiener, G. TITAN: Thunderstorm Identification, Tracking, Analysis, and Nowcasting-A Radar-based Methodology. J. Atmos. Ocean. Technol. 1993, 10, 785-797. [CrossRef]

11. Li, L.; Schmid, W.; Joss, J. Nowcasting of Motion and Growth of Precipitation with Radar over a Complex Orography. J. Appl. Meteorol. 1995, 34, 1286-1300. [CrossRef]

12. Germann, U.; Zawadzki, I. Scale-Dependence of the Predictability of Precipitation from Continental Radar Images. Part I: Description of the Methodology. Mon. Weather Rev. 2002, 130, 2859-2873. [CrossRef]

13. Bowler, N.E.; Pierce, C.E.; Seed, A. Development of a precipitation nowcasting algorithm based upon optical flow techniques. J. Hydrol. 2004, 288, 74-91. [CrossRef]

14. Ruzanski, E.; Chandrasekar, V.; Wang, Y. The CASA Nowcasting System. J. Atmos. Ocean. Technol. 2011, 28, 640-655. [CrossRef]

15. Mandapaka, P.V.; Germann, U.; Panziera, L.; Hering, A. Can Lagrangian Extrapolation of Radar Fields Be Used for Precipitation Nowcasting over Complex Alpine Orography? Weather Forecast. 2012, 27, $28-49$. [CrossRef]

16. Foresti, L.; Sideris, I.V.; Panziera, L.; Nerini, D.; Germann, U. A 10-year radar-based analysis of orographic precipitation growth and decay patterns over the Swiss Alpine region. Q. J. R. Meteorol. Soc. 2018, 144, 2277-2301. [CrossRef]

17. Bližňák, V.; Sokol, Z.; Zacharov, P. Nowcasting of deep convective clouds and heavy precipitation: Comparison study between NWP model simulation and extrapolation. Atmos. Res. 2017, 184, 24-34. [CrossRef]

18. Steinheimer, M.; Haiden, T. Improved nowcasting of precipitation based on convective analysis fields. Adv. Geosci. 2007, 10, 125-131. [CrossRef]

19. Ricciardelli, E.; Di Paola, F.; Gentile, S.; Cersosimo, A.; Cimini, D.; Gallucci, D.; Geraldi, E.; Larosa, S.; Nilo, S.T.; Ripepi, E.; et al. Analysis of Livorno Heavy Rainfall Event: Examples of Satellite-Based Observation Techniques in Support of Numerical Weather Prediction. Remote Sens. 2018, 10, 1549. [CrossRef]

20. Di Paola, F.; Ricciardelli, E.; Cimini, D.; Romano, F.; Viggiano, M.; Cuomo, V. Analysis of Catania Flash Flood Case Study by Using Combined Microwave and Infrared Technique. J. Hydrometeorol. 2014, 15, 1989-1998. [CrossRef]

21. Dixon, M.; Li, Z.; Lean, H.; Roberts, N.; Balland, S. Impact of data assimilation on forecasting convection over the United Kingdom using a high-resolution version of the met office unified model. Mon. Weather Rev. 2009, 137, 1562-1584. [CrossRef]

22. Da Silva Neto, C.P.; Barbosa, H.A.; Beneti, C.A.A. A method for convective storm detection using satellite data. Atmósfera 2016, 29, 343-358. [CrossRef]

23. Marco, M.; Victor, V.; Dirk, S.; Clemens, S. Assimilation of radar and satellite data in mesoscale models: A physical initialization scheme. Meteorol. Z. 2008, 17, 887-902. [CrossRef] 
24. Roberts, R.D.; Rutledge, S. Nowcasting Storm Initiation and Growth Using GOES-8 and WSR-88D Data. Weather Forecast. 2003, 18, 562-584. [CrossRef]

25. Zinner, T.; Mannstein, H.; Tafferner, A. Cb-TRAM: Tracking and monitoring severe convection from onset over rapid development to mature phase using multi-channel Meteosat-8 SEVIRI data. Meteorol. Atmos. Phys. 2008, 101, 191-210. [CrossRef]

26. Mecikalski, J.R.; Bedka, K.M.; Paech, S.J.; Litten, L.A. A Statistical Evaluation of GOES Cloud-Top Properties for Nowcasting Convective Initiation. Mon. Weather Rev. 2008, 136, 4899-4914. [CrossRef]

27. Mecikalski, J.R.; MacKenzie, W.M.; Koenig, M.; Muller, S. Cloud-Top Properties of Growing Cumulus prior to Convective Initiation as Measured by Meteosat Second Generation. Part I: Infrared Fields. J. Appl. Meteorol. Climatol. 2010, 49, 521-534. [CrossRef]

28. Mecikalski, J.R.; MacKenzie, W.M., Jr.; König, M.; Muller, S. Cloud-Top Properties of Growing Cumulus prior to Convective Initiation as Measured by Meteosat Second Generation. Part II: Use of Visible Reflectance. J. Appl. Meteorol. Climatol. 2010, 49, 2544-2558. [CrossRef]

29. Sieglaff, J.M.; Cronce, L.M.; Feltz, W.F.; Bedka, K.M.; Pavolonis, M.J.; Heidinger, A.K. Nowcasting Convective Storm Initiation Using Satellite-Based Box-Averaged Cloud-Top Cooling and Cloud-Type Trends. J. Appl. Meteorol. Climatol. 2011, 50, 110-126. [CrossRef]

30. Siewert, C.W.; Koenig, M.; Mecikalski, J.R. Application of Meteosat second generation data towards improving the nowcasting of convective initiation. Meteorol. Appl. 2010, 17, 442-451. [CrossRef]

31. Merk, D.; Zinner, T. Detection of convective initiation using Meteosat SEVIRI: Implementation in and verification with the tracking and nowcasting algorithm Cb-TRAM. Atmos. Meas. Tech. 2013, 6, 1903-1918. [CrossRef]

32. Mecikalski, J.R.; Williams, J.K.; Jewett, C.P.; Ahijevych, D.; LeRoy, A.; Walker, J.R. Probabilistic 0-1-h Convective Initiation Nowcasts that Combine Geostationary Satellite Observations and Numerical Weather Prediction Model Data. J. Appl. Meteorol. Climatol. 2015, 54, 1039-1059. [CrossRef]

33. Koenig, M.; de Coning, E. The MSG Global Instability Indices Product and Its Use as a Nowcasting Tool. Weather Forecast. 2009, 24, 272-285. [CrossRef]

34. Atencia, A.; Rigo, T.; Sairouni, A.; Moré, J.; Bech, J.; Vilaclara, E.; Cunillera, J.; Llasat, M.C.; Garrote, L. Improving QPF by blending techniques at the Meteorological Service of Catalonia. Nat. Hazards Earth Syst. Sci. 2010, 10, 1443-1455. [CrossRef]

35. De Coning, E.; Koenig, M.; Olivier, J. The combined instability index: A new very-short range convection forecasting technique for southern Africa. Meteorol. Appl. 2011, 18, 421-439. [CrossRef]

36. Cintineo, J.L.; Pavolonis, M.J.; Sieglaff, J.M.; Lindsey, D.T.; Cronce, L.; Gerth, J.; Rodenkirch, B.; Brunner, J.; Gravelle, C. The NOAA/CIMSS ProbSevere Model: Incorporation of Total Lightning and Validation. Weather Forecast. 2018, 33, 331-345. [CrossRef]

37. Nerini, D.; Foresti, L.; Leuenberger, D.; Robert, S.; Germann, U. A Reduced-Space Ensemble Kalman Filter Approach for Flow-Dependent Integration of Radar Extrapolation Nowcasts and NWP Precipitation Ensembles. Mon. Weather Rev. 2019, 147, 987-1006. Available online: https://journals.ametsoc.org/mwr/ article-pdf/147/3/987/4849993/mwr-d-18-0258_1.pdf (accessed on 8 August 2020). [CrossRef]

38. Cintineo, J.L.; Pavolonis, M.J.; Sieglaff, J.M.; Heidinger, A.K. Evolution of Severe and Nonsevere Convection Inferred from GOES-Derived Cloud Properties. J. Appl. Meteorol. Climatol. 2013, 52, 2009-2023. [CrossRef]

39. Sandmæl, T.N.; Homeyer, C.R.; Bedka, K.M.; Apke, J.M.; Mecikalski, J.R.; Khlopenkov, K. Evaluating the Ability of Remote Sensing Observations to Identify Significantly Severe and Potentially Tornadic Storms. J. Appl. Meteorol. Climatol. 2019, 58, 2569-2590. [CrossRef]

40. Mecikalski, J.R.; Rosenfeld, D.; Manzato, A. Evaluation of geostationary satellite observations and the development of a 1-2 h prediction model for future storm intensity. J. Geophys. Res. Atmos. 2016, 121, 6374-6392. [CrossRef]

41. Senf, F.; Deneke, H. Satellite-Based Characterization of Convective Growth and Glaciation and Its Relationship to Precipitation Formation over Central Europe. J. Appl. Meteorol. Climatol. 2017, 56, 1827-1845. [CrossRef]

42. Patou, M.; Vidot, J.; Riédi, J.; Penide, G.; Garrett, T.J. Prediction of the Onset of Heavy Rain Using SEVIRI Cloud Observations. J. Appl. Meteorol. Climatol. 2018, 57, 2343-2361. [CrossRef] 
43. Met Office. Fact Sheet No.3: Water in the Atmosphere; Met Office/National Meteorological Library and Archive: Exeter, UK, 2007. Available online: https:/ / web.archive.org/web/20120114162401/http:/ / www.metoffice. gov.uk/media/pdf/4/1/No._03_-_Water_in_the_Atmosphere.pdf (accessed on 8 August 2020).

44. Corazzon, P.; Giuliacci, E. La Meteorologia Per Tutti; Alpha Test: Milano, Italy, 2008.

45. Hanachi, C.; Bénaben, F.; Charoy, F. (Eds.) The Dewetra Platform: A Multi-perspective Architecture for Risk Management during Emergencies. In Information Systems for Crisis Response and Management in Mediterranean Countries; Springer International Publishing: Cham, Switzerland, 2014; pp. 165-177.

46. Pucillo, A.; Miglietta, M.M.; Lombardo, K.; Manzato, A. Application of a simple analytical model to severe winds produced by a bow echo like storm in northeast Italy. Meteorol. Appl. 2020, 27, e1868. [CrossRef]

47. Giaiotti, D.B.; Giovannoni, M.; Pucillo, A.; Stel, F. The climatology of tornadoes and waterspouts in Italy. Atmos. Res. 2007, 83, $534-541$. [CrossRef]

48. Vulpiani, G.; Pagliara, P.; Negri, M.; Rossi, L.; Gioia, A.; Giordano, P.; Alberoni, P.P.; Cremonini, R.; Ferraris, L.; Marzano, F.S. The Italian radar network within the national early-warning sys-tem for multi-risks management. In Proceedings of the Fifth European Con-ference on Radar in Meteorology and Hydrology (ERAD 2008), Helsinki, Finland, 30 June-4 July 2008; Finnish Meteorological Institute: Helsinki, Finland, 2008; Volume 184.

49. Rinollo, A.; Vulpiani, G.; Puca, S.; Pagliara, P.; Kaňák, J.; Lábó, E.; Okon, L.; Roulin, E.; Baguis, P.; Cattani, E.; et al. Definition and impact of a quality index for radar-based reference measurements in the H-SAF precipitation product validation. Nat. Hazards Earth Syst. Sci. 2013, 13, 2695-2705. [CrossRef]

50. Molini, L.; Parodi, A.; Rebora, N.; Craig, G.C. Classifying severe rainfall events over Italy by hydrometeorological and dynamical criteria. Q. J. R. Meteorol. Soc. 2011, 137, 148-154. [CrossRef]

51. Schmetz, J.; Pili, P.; Tjemkes, S.; Just, D.; Kerkmann, J.; Rota, S.; Ratier, A. An introduction to Meteosat second generation (MSG). Bull. Am. Meteorol. Soc. 2002, 83, 977-992. [CrossRef]

52. Adler, R.F.; Fenn, D.D. Thunderstorm Intensity as Determined from Satellite Data. J. Appl. Meteorol. (1962-1982) 1979, 18, 502-517. [CrossRef]

53. Hamada, A.; Takayabu, Y.N. Convective cloud top vertical velocity estimated from geostationary satellite rapid-scan measurements. Geophys. Res. Lett. 2016, 43, 5435-5441. [CrossRef]

54. Liang, K.; Shi, H.; Yang, P.; Zhao, X. An Integrated Convective Cloud Detection Method Using FY-2 VISSR Data. Atmosphere 2017, 8, 42. [CrossRef]

55. NOAA. Glossary of Forecast Verification Metrics; NOAA: Silver Spring, MD, USA. Available online: https: / / www.nws.noaa.gov /oh/rfcdev/docs/Glossary_Verification_Metrics.pdf (accessed on 8 August 2020). 